\title{
Erythrocytic Anaplasmosis in Cattle: A Case Study
}

\author{
Tripti Gurjar, Jitendra Kant Nagar, Rohitash Dhadhich, Om Prakash Meena, \\ Amit Meena and Rahul Tiwari
}

\begin{abstract}
Post Graduate Institute of Veterinary Education and Research, Jaipur (Rajasthan), India Rajasthan University of Veterinary and Animal Sciences, Bikaner, India
\end{abstract}

*Corresponding author

\begin{tabular}{|l|}
\hline K e y w o r d s \\
Anaplasma, \\
Rickettsial, \\
Imidocarb \\
dipropionate, Cattle, \\
Beet
\end{tabular}

\section{Introduction}

Anaplasma is an one of the most important
tick-born disease in ruminants. In ruminants,
five species including Anaplasma marginale,
Anaplasma centrale, Anaplasma bovis,
Anaplasma phagocytophilium and Anaplasma

Anaplasma is an one of the most important
tick-born disease in ruminants. In ruminants,
five species including Anaplasma marginale,
Anaplasma centrale, Anaplasma bovis,
Anaplasma phagocytophilium and Anaplasma

Anaplasma is an one of the most important
tick-born disease in ruminants. In ruminants,
five species including Anaplasma marginale,
Anaplasma centrale, Anaplasma bovis,
Anaplasma phagocytophilium and Anaplasma

Anaplasma is an one of the most important
tick-born disease in ruminants. In ruminants,
five species including Anaplasma marginale,
Anaplasma centrale, Anaplasma bovis,
Anaplasma phagocytophilium and Anaplasma

Anaplasma is an one of the most important
tick-born disease in ruminants. In ruminants,
five species including Anaplasma marginale,
Anaplasma centrale, Anaplasma bovis,
Anaplasma phagocytophilium and Anaplasma

\section{A B S T R A C T}

Anaplasma is one of the most rickettsiale diseases in ruminants. Five species including Anaplasma marginale, Anaplasma centrale, Anaplasma bovis, Anaplasma phagocytophilium and Anaplasma ovis are recognized in ruminant animals. Anaplasma causes major economic losses to the livestock owner. Anaplasma is mainly transmitted by mechanical way such as by biting flies, lice and biological by different tick species and fomites in livestock. A six year old cross breed cow was brought to Veterinary Clinical Complex of Post Graduate Institute of Veterinary Education and Research, Jaipur (Rajasthan) with the history of anorexia, shivering and respiratory distress, and decreased milk quantity since a week. On close physical examination, enlarged parotid lymph nodes and conjunctival mucous membranes with whitish or pale were noticed. Physiological parameters like rectal temperature, heart rate and respiratory rates were found to be $106^{\circ} \mathrm{F}$, 135 beats per minute and 45 per minute respectively. On hematological examination, hemoglobin was found to be low i.e., $3.2 \mathrm{~g} / \mathrm{dl}$. Peripheral blood smear examination revealed the presence of Anaplasma marginalis organisms in the erythrocytes with Geimsa Stain. Based on these findings a diagnosis of bovine erythrocytic Anaplasma was made and the case was treated with Oxytetracycline @ 5-10 mg/ml body weight, intravenous; Imidocarb dipropionate @ $2.5 \mathrm{ml} / 100 \mathrm{Kg}$ Body weight, haematinic consists of Iron Sorbitol Citric acid complex $50 \mathrm{mg}$ + Folic Acid $500 \mathrm{mg}+$ Hydroxycobalamin Acetate 50 mg per milliliter @ 1 ml/50 Kg body weight, intramuscularly included Thiamine+ Pyridoxine + Cynocobalamine @ 5-10 ml, intramuscularly or intravenously and Phenramine Maleate @ 0.5-1.5 mg/Kg body weight, intramuscularly, Ivermectin @ 0.2 $\mathrm{mg} / \mathrm{Kg}$ body weight, subcutaneous and also advised for beet in feeding for increasing the haemoglobin. Improvement was noticed after 5 days of treatment. ovis are recognized (Inokuma, 2007). The genus Anaplasma was described for the first time by Sir Arnold Theiler, who first documented that "marginal points" were found responsible to cause some specific disease (Theiler, 1910). In tropical areas, Anaplasma causes major economic losses to 
the livestock owners in shape of mortality in domestic animals and also causes health related problems such as low production and poor growth rate (Jonsson et al., 2008; Alfredo et al., 2005). Anaplasma is mainly transmitted by mechanical way such as by biting flies, lice and biological by different tick species and fomites in livestock. In livestock, there are a several Tabanus species (horseflies) and also several mosquitos have been confirmed in experimental transmission of Anaplamosis. It is suspected that tick-born disease is main cause for 50 per cent cattle mortality (Martins et al., 2008). It has also been observed that adult ticks (Dermacentor occidentalis) are mainly responsible for transmission of Anaplasma marginale in livestock, since this adults species (Dermacentor occidentalis) usually suck the blood from cattle and deer, it is likely that there is inter-transmission occur deer and deer, deer and cattle, cattle and deer (Osebold et al., 1962). Bovine Anaplasmosis a severe disease of cattle and characterized by advanced hemolytic anemia, fever, abortion, which can lead to a dramatic decrease milk production and in some cases death of the affected animals (Noaman et al., 2009; Ashuma et al., 2013; Smith, 2015; Noamanand Bastani, 2016). The disease, although normally causes sporadic mortalities may result in high morbidity when herd immunity is compromised and two species of concern are Anaplasma marginale, Anaplasma central, with the former being more pathogenic (Abba et al., 2016). In cattle, Anaplasma is caused by Anaplasma marginale and are intraerythrocytic microorganisms of the order of rickettsiales. Severity of the disease is related to various factors such as virulence of the strain, age related host susceptibility and breed resistance. Animals that recover from the disease may remain carriers for life and thus becoming reservoirs for transmission to other susceptible hosts. In livestock, these haemoparasitic diseases make great loss of about 250 million, and play main constraint in production and development of livestock sector in many developing countries of world (Radostits et al., 2000). Smith, (2015) concluded that for effective control of Anaplasma, early diagnosis and treatment is essential, while continuous screening should be practiced to control the disease.

The present communication describes with efficacy of anti-anaplasmosis (Imidocarb dipropionate) drug and haematinic agents (Iron Sorbitol Citric acid complex $50 \mathrm{mg}+$ Folic Acid $500 \mathrm{mg}+$ Hydroxycobalamin Acetate $50 \mathrm{mg}$ per milliliter).

\section{Case History}

In present investigation, one clinical cases of Anaplasma in crossbred cattle recorded at Veterinary Clinical Complex, Post Graduate Institute of Veterinary Education \& Research, Jaipur (Raj.) during March, 2019. The all information pertaining to age, sex, breed, season and other parameters was recorded and clinical manifestation observed and examined in respect of duration of illness, body temperature, pulse rate, respiration rate and color of mucous membrane, skin and hair coat, body condition were critically examined for presence of ticks and flies.

Haematological examination revealed haemoglobin was very low in the range of 3.2 $\mathrm{g} / \mathrm{dl}$, lymphocytopinea, eosinopinea, monocytophilia and also examined blood smear with direct blood collection from ear vein for the blood parasite. The clinical diagnosis was established by the presence of high temperature and presence of Anaplasma marginale in erythrocyte.

One crossbred cattle were treated with a single dose of Imidocarb dipropionate $2.5 \mathrm{ml} / 100$ $\mathrm{Kg}$ body weight deep, intramuscularly. In supportive therapy, Oxytetracycline @ 5-10 
$\mathrm{mg} / \mathrm{ml}$ body weight, intravenous; Meloxicam+Paracetamol @ 0.5mg/Kg body weight, intramuscular as antipyretic, haematinic consists of Iron Sorbitol Citric acid complex $50 \mathrm{mg}+$ Folic Acid $500 \mathrm{mg}+$ Hydroxycobalamin Acetate $50 \mathrm{mg}$ per milliliter @ $1 \mathrm{ml} / 50 \mathrm{Kg}$ body weight, intramuscularly included Thiamine+ Pyridoxine + Cynocobalamine @ 5-10 ml, intramuscularly or intravenously and Phenramine Maleate @ 0.5-1.5 mg/Kg body weight, intramuscularly, Ivermectin @ 0.2 $\mathrm{mg} / \mathrm{Kg}$ body weight, subcutaneous and also advised for beet in feeding for increasing the haemoglobin.

After the treatment schedule, on fifth day, body temperature, appetite, skin and hair coat, color of mucous membrane and respiration rate were restored to normal in affected cattle.

\section{Results and Discussion}

In India, rearing of crossbred cattle because that crossbred cattle are beneficial and important to farmers according to production and economically (BAHS, 2012).

Bovine Anaplasma caused by Anaplasma marginale is the major cause of morbidity and mortality in the tropics and sub-tropics, particularly in exotic and crossbred cattle (Singh et al., 2012).

In present investigation, the first visible sign observed was rise in emaciated body condition (Fig. 1), body temperature $\left(106.2^{\circ} \mathrm{F}\right)$ with palpable enlargement of parotid lymph nodes, pale mucous membrane (Fig. 2 and 3). Since the ticks were found attached to the ear region, the enlargement of lymph node and pyrexia could be attributed to development stages of the parasites (Soulsby, 1982; Kolte et al., 2003; Radostits et al., 2007; Mahadappa et al., 2017). Soulsby (1982) also reviewed that the disease commences with fever and after the onset of fever animals cease to eat. Tachycardia (135/ minute), increased respiration, pale mucous membrane, severe jaundice, decreased milk production were observed in present investigation could be attributed to anemia and support the findings of Richey and Palmaer, (1990); Birdane et al., (2006); Kocan et al., (2010) and Bal et al., (2017).

Haematological parameters showed significant decrease haemoglobin $(3.2 \mathrm{~g} / \mathrm{dl})$, Similar findings were earlier reported by Maadappa and Rakesh, (2016); Bal et al., (2017) and also found lymphocytopinea, eosinopinea, monocytophilia and also examined blood smear with direct blood collection from ear vein for the blood parasite. The clinical diagnosis was established by presence of Anaplasma marginale in erythrocyte with Giemsa stain using standard procedure (Fig. 4 and 5). Similar findings were earlier reported by Noaman and Shayan (2010), Singh et al., (2012), OIE (2015) and (Bitrus et al., 2018).

Faster recovery might be attributed to the early diagnosis and higher dose of Oxytetracycline and Imidocarb dipropionate used in the present case. To combat anemic changes haematinics drugs with also advised of beet for increasing haemoglobin level as a supporative therapy were also prescribed.

This is in agreement with the findings of Ananda et al., (2009); Afifi et al., (2014) and Doyle et al., (2016). Ananda et al., (2009) who stated that Oxytetracycline is more effective at higher doses in Anaplasma.

Afifi et al., (2014) and Doyle et al., (2016) concluded that Imidocarb dipropionate is effective in Anaplasma condition.

Erythrocytic Anaplasma are rickettsiales disease of crossbred cattle and caused by various Anaplasma species. 
Fig.1 Emaciated cattle due to Anaplasma marginale

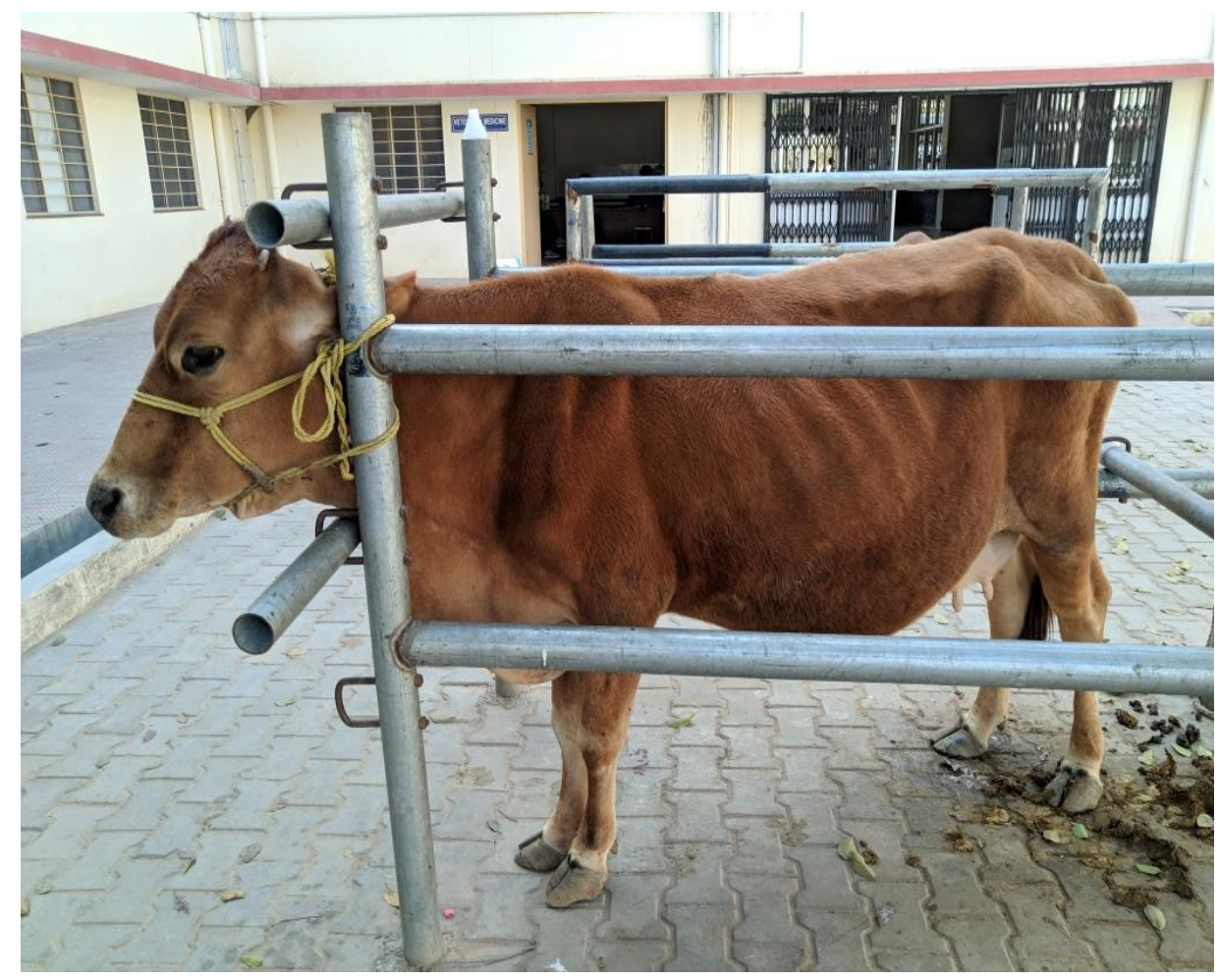

Fig.2 Pale vaginal mucous membrane in Anaplasma in Cattle

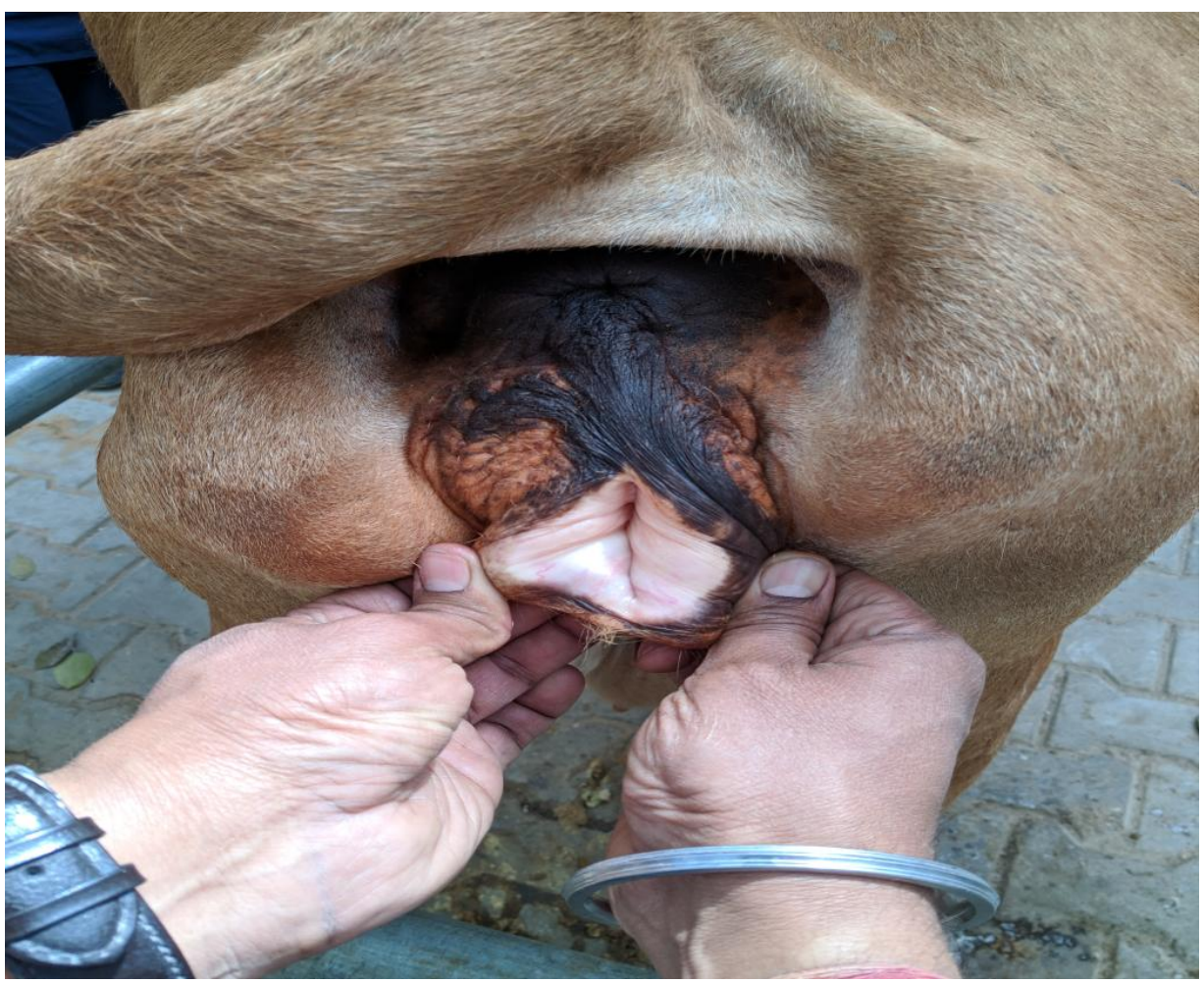


Fig.3 Pale conjunctiva mucous membrane in Anaplasma in Cattle

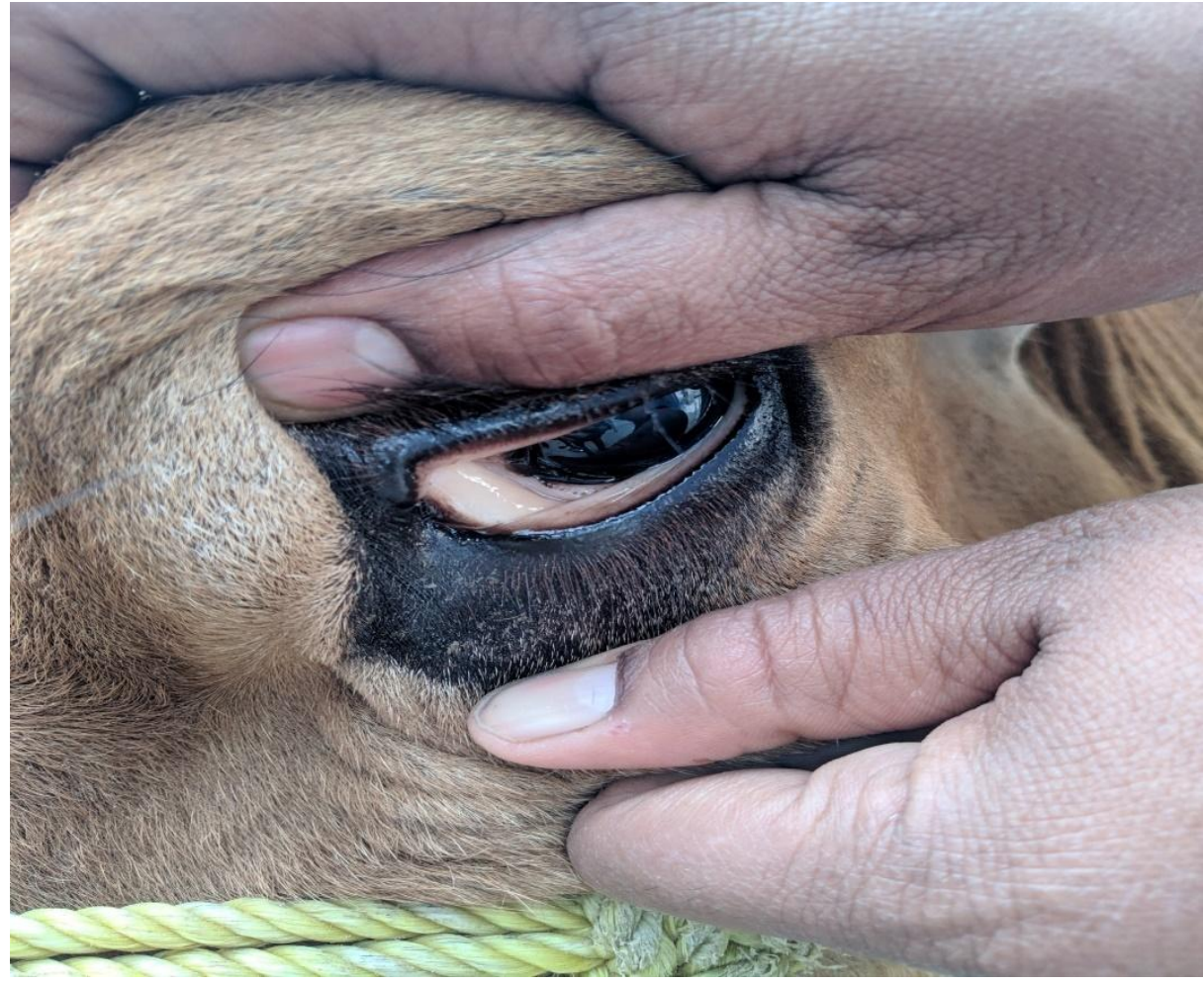

Fig.4 Erythrocytes infected with Anaplasma marginale (arrowed)

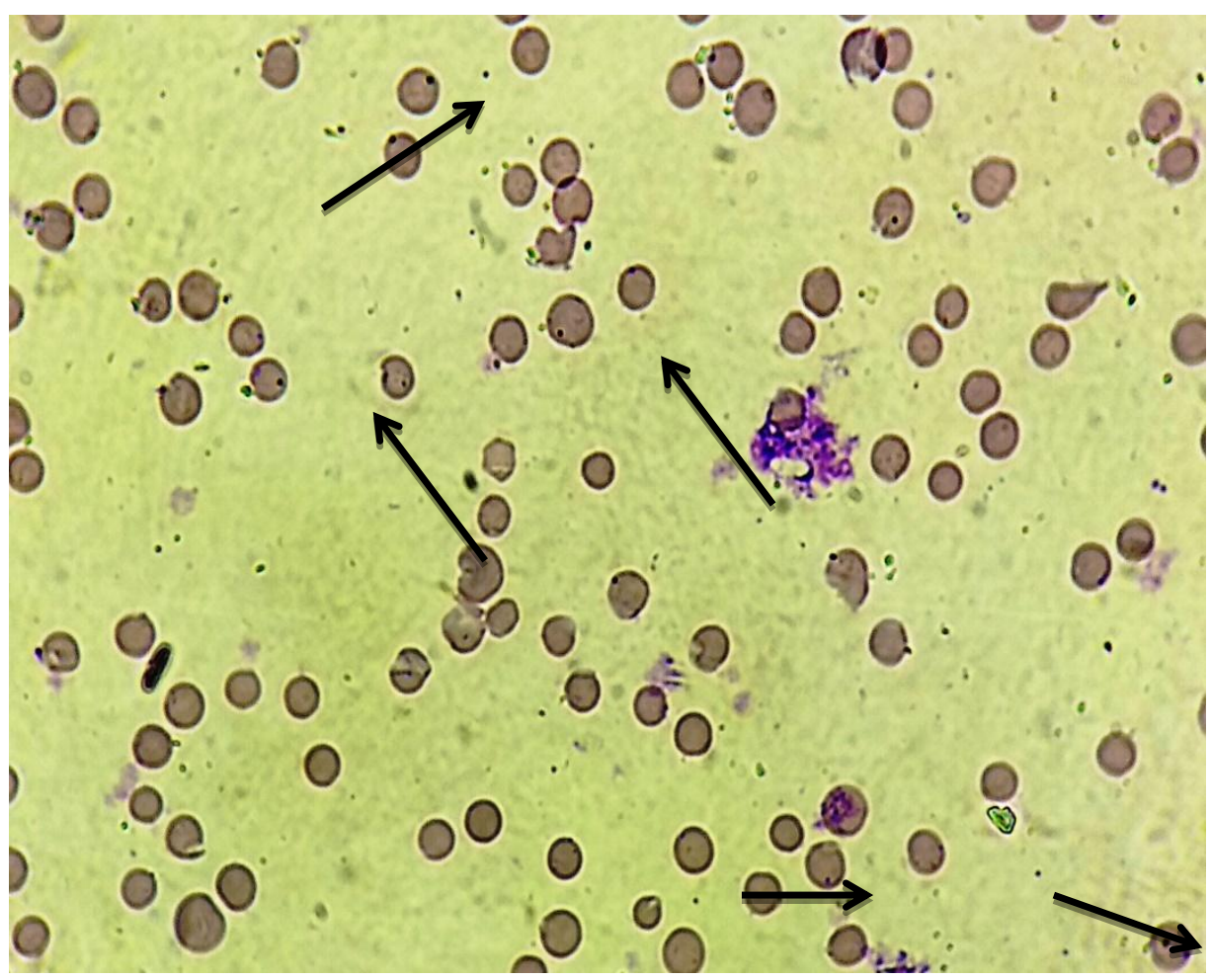


Fig.5 Erythrocytes infected with Anaplasma marginale (arrowed)

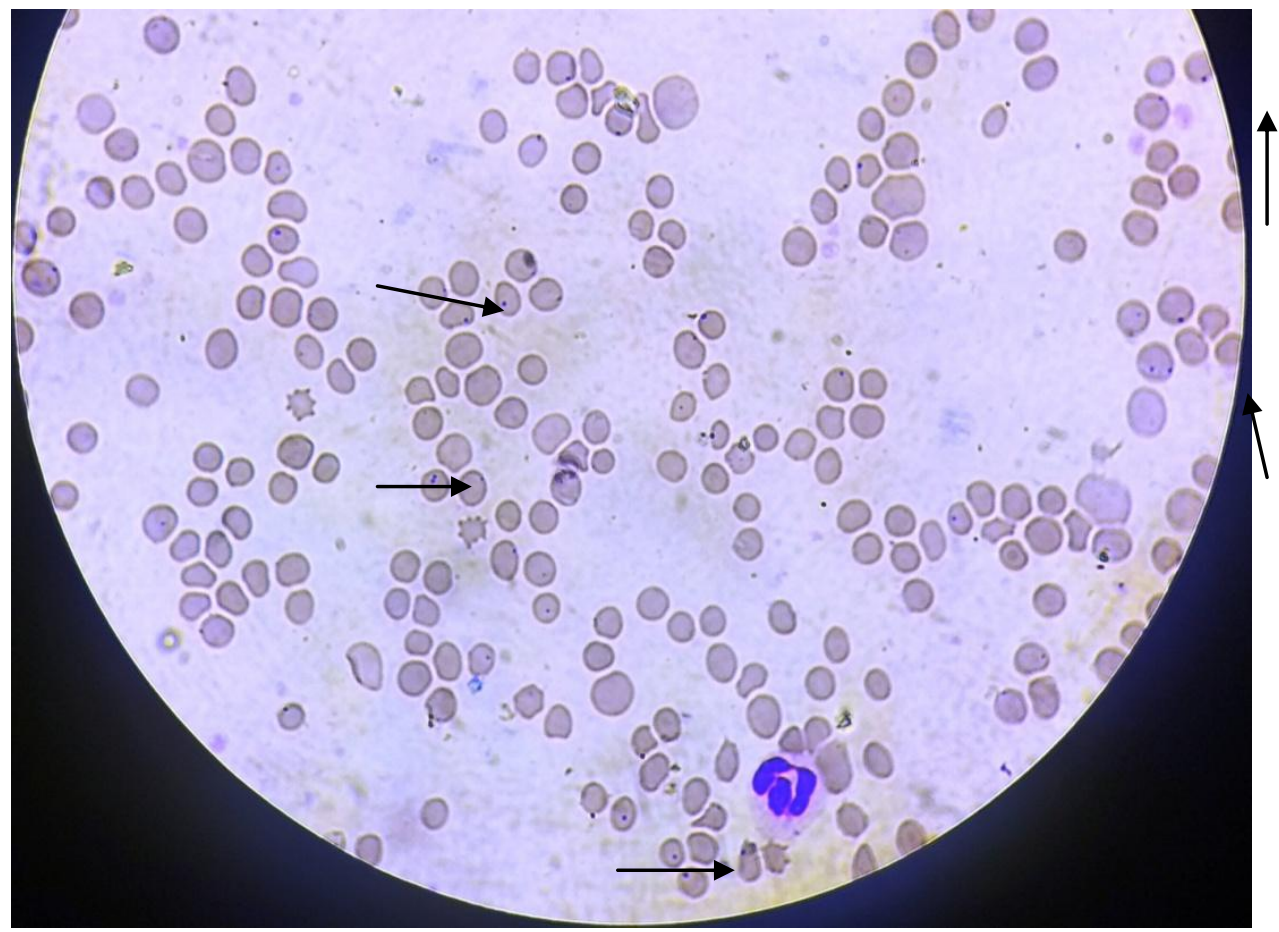

The anaplasmosis infection is recorded in the areas where not adopted proper management practices like as time to time spraying, dipping and cleanliness in herd.

In Anaplasma condition, best drug of choice is Imidocarb dipropionate with high dose of Oxytetracycline. There should be give supportive treatment with antipyretic and haematinic agents like as Ferritas (Iron Sorbitol Citric acid complex $50 \mathrm{mg}+$ Folic Acid $500 \mathrm{mg}+$ Hydroxycobalamin Acetate 50 mg per milliliter), multivitamine and Ivermection for prevention of Anaplasmosis and also advised for beet in feeding for increasing the haemoglobin.

\section{Conflict of Interest}

The authors have none to declare.

\section{Authors Contribution}

All authors contributed equally.

\section{References}

Abba Y, Jesse F A J, Sadiq M, Ibrahim H H, Chung E L T, Bitrus A A, Mohd Lila M A, Hambali, I U (2016). Clinical management and gross pathological findings of a severe anaplamosis in a dairy cow. Journal of. Advance Veterinary and Animal Research, 3(2): 195- 199.

Afifi N A, Shihata m, El-Zorba H Y, Ismail I M (2014). Effects of Imidocarbdipropionate on the immune response to foot and mouth disease vaccine in healthy and Anaplasma infected calves. Veterinary World, 7: 162-167.

Alfredo A A N, Jonsson N N, Finch T M, Neves L, Molloy J B, Jorgensen W K (2005). Serological survey of Babesia bovis and Anaplasma marginale in cattle in Tete Province, Mozambique. Tropical Animal and Health Production, 37(2):121-131. 
Ananda KJ, D'Souza PE, Puttalakshmamma GC (2009) Prevalence of Haemoprotozoan diseases in crossbred cattle in Bangalore north. Veterinay World, 2(1):15-16,

Ashuma, Sharma A, Singla L D, Kaur P, Bal M S, Batth B K and Juyal P D (2013). Prevalence and haemato-biochemical profile of Anaplasma marginale infection in dairy animals of Punjab (India). Asian Pacific Journal of Biomedicine, 6(2): 139-144.

BAHS (2012). Basic Animal Husbandry Statistics. Government of India, Ministry of Agriculture, Department of Animal Husbandry, Dairying and Fishries, KrishiBhawan, New Delhi.

Bal M S, Mahajan V, Filla G, Singh C K, Kaur P and Sharma S (2017). Outbreaks of Anaplasma in dairy cattle in Punjab, India. Journal of Animal Research, 7 (5): 885-889.

Birdane M F, Sevinc F and Derinbay O (2006). Anaplasma marginale infections in dairy cattle: clinical disease with high seroprevalence. The Bulletin of the Veterinary Institute in Pulway.,50: 467470.

Bitrus A A, Abba Y, Jesse A F F, Peter I D (2018). Seroprevalence of Anaplasma in dairy cattle from Peninsular Malaysia. Advances in animal and Veterinary Science, 6 (2): 70-74.

Doyle R L, Fritzen A, Bottari N B, Alves M S, Silva A D, Morsch V M, Schetinger M R C, Martins J R, Santos J S, Marchado G, Silva A S (2016). Imidocarbdipropionate in the treatment of Anaplasma marginale in cattle: effects on enzymes of the antioxidant, cholinergic and adenosingergic systems. Macrobial Pathogenesis, 97: 226-230.

Inokuma H (2007) Vectors and reservoir hosts of Anaplasmataceae. In: Raoult D, Parola P, eds. Rickettsial Diseases.
Taylor \& Grancis Group LLC, New York, pp. 199-212.

Jonsson N N, Bock R E, Jorgensen W K (2008). Productivity and health effects of Anaplasma and Babesiosis on bosindicus cattle and their crosses, and the effects of differing intensity of tick control in Australia. Veterinary Parasitology 155:1: 1-9.

Kocan K M, Fuente J de la, Blouin E F, Coetzee J F and Ewing S A (2010). The natural history of Anaplasma marginale. Veterinary Parasitology, 167(2-4): 95-107.

Kolte S W, Maske S K, Gaholod B M, Kurkure N V (2003). Ehrlichiosis in cattle and buffaloes from Vidarbha, India. Indian Veterinary Journal, 80(5): 399-400.

Mahadappa P, Dhanalakshmi H, Rakesh R L, Thimmareddy P M, NarayanaBhat M (2017). Monocytic Anaplasma in a cow: A case study. Journal of Parasitic Disease, 41(3): 687-688

Martins T M (2008). Detection of bovine Babesiosisin Mozambique by a novel semi nested hot-start PCR method. Veterinary Parasitology, 153(3-4): 225230.

Noaman V, Bastani D (2016) Molecular study on infection rates of Anaplasma ovis and Anaplasma marginale in sheep and cattle in West-Azerbaijan province, Iran. Veterinary Research Forum, 7: 163-167.

Noaman V, Shayan P (2010). Comparison of microscopy and PCR-RFLP for detection of Anaplasma marginale in carrier cattle. Iranian Journal Microbiology, 2: 89-94.

Noaman V, Shayan P, Amininia N (2009). Molecular diagnostic of Anaplasma marginale in carrier cattle. Iranian Journal Parasitology, 4: 26-33.

Osebold J W, J F Christensen, W M Longhurst, M N Rosen (1962). Latent 
Anaplasma marginale infection in wild deer demonstrated by calf inoculations. Cornell Veterinarian, 49: 97-115.

Radostits O M, Gay C C, Hinchcliff K W, Constable P D. (2007). Veterinary Medicine, A text book of the disease of cattle, horses, sheep, pigs and goats. $10^{\text {th }}$ edition London: W.B. Suanders, 14551459 .

Radostits O M, Gay D C, Blood D C, Hinchcliff K W (2000). Veterinary Medicine. A Textbook of the Diseases of Cattle, Sheep, Pigs, Goats and Horses, 9th Ed. W.B. Saunders, Philadelphia.

Richey E J and Palmer G H (1990). Bovine Anaplasma. Compendium and Continuing Education for Practicing Veterinarian, 12(11): 1661-1668.
Singh H, Haque M, Singh N K, Rath S S (2012). Molecular detection of Anaplasma marginale infection in carrier cattle. Ticks tick-borne Disease, 3(1): $55-58$

Smith B P (2015). Large animal internal medicine, 5th Edition. St. Louis, MO: Mosby. 1054-1056.

Soulsby E J L (1982). Helminths, arthropods and protozoa of domesticated animals, $7^{\text {th }}$ Edn. BailliereTindall, Elsevier.

Theiler A (1910). Gall sickness of South Africa (Anaplasma of Cattle). Journal of Comparative Pathology Ther. 23: 98115.

World Organization for Animal Health, OIE (2015). Bovine Anaplasma. OIE Terrestial Manual.

\section{How to cite this article:}

Tripti Gurjar, Jitendra Kant Nagar, Rohitash Dhadhich, Om Prakash Meena, Amit Meena and Rahul Tiwari. 2019. Erythrocytic Anaplasmosis in Cattle: A Case Study. Int.J.Curr.Microbiol.App.Sci. 8(07): 1932-1939. doi: https://doi.org/10.20546/ijcmas.2019.807.230 